at 550 p.p.m., the world will need to reduce its projected business-as-usual emissions by about 1,000 gigatonnes of carbon over the next century. Seven stabilization wedges worth would achieve 175 gigatonnes, leaving a considerable gap, even if the total business-asusual emissions have been overestimated by a factor of two or more.

It is perhaps Sweet's underestimation of the magnitude of the challenge that leads him to dismiss the prospects for renewables and carbon sequestration in favour of a focus on reducing the emissions from coal. If stabilization at twice pre-industrial levels is to happen, not only will a focus on coal, renewables and sequestration be needed, but many experts argue that there will need to be a fundamental transformation of the global energy system. Based on its misplaced optimism of a relatively quick and easy fix, Kicking the Carbon Habit quickly dismisses such perspectives.
Many believe that if climate change can be dealt with relatively easily, then there would also be little need to adapt to it. This sort of thinking may explain why the issue of adaptation plays no role in the book. Overlooking adaptation in any discussion of dimate policy is a sign that the challenge posed by climate change has been fundamentally mischaracterized - not only because the world is already committed to some degree of dimate change, but also because adaptation makes sense under any future climate scenario.

In the end, Kicking the Carbon Habit is a deeply flawed book with considerable potential to mislead its readers about policies related to climate change. This is a shame because its discussions of climate science are both entertaining and informative.

Roger A. Pielke, Jr is at the Center for Science and Technology Policy Research, University of Colorado/CIRES, Boulder, Colorado 80309, USA.

\title{
The road to phage therapy
}

\author{
Viruses vs. Superbugs: A Solution to the \\ Antibiotics Crisis? \\ by Thomas Häusler \\ Macmillan Science: 2006. 256 pp. \\ $£ 16.99, \$ 24.95$
}

\section{Sankar Adhya \& Carl Merril}

The first evidence for a viral-like agent with antibacterial properties was reported by $\mathrm{M}$. E. Hankin in 1896. Found in the Ganges river in India, it was temperature sensitive, capable of passing through a porcelain filter, and could reduce titres of the bacterium Vibrio cholerae in laboratory culture. Hankin suggested that it might help to decrease the incidence of cholera in people using water from the Ganges.

The viral nature of such antibacterial agents became clearer following the observation of agents capable of lysing bacterial cultures by Frederick Twort and Felix d'Herrelle in 1915 and 1917, respectively. It was d'Herrelle who named these agents bacteriophages and championed their use in treating infectious diseases. $\mathrm{He}$ and his colleagues introduced phage therapy throughout the world, with major efforts in India, Egypt, the United States and the Soviet Union. Unfortunately, these clinical applications were initiated before certain microbiological aspects of phage strains, such as their narrow host range, were fully appreciated. In addition, clinical investigations in the 1920 s and ' 30 s were based largely on anecdotal evidence - scientific and statistically relevant clinical trials were only introduced in the 1940 s, primarily in the United States and Britain. The clinical use of phage therapy without the underlying scientific support needed to assure a high level of clinical effectiveness, combined with the development of antibiotics during the Second World War, served to marginalize the use of phage therapy in most Western countries.

There have been many reviews of phage therapy and some books, but few provide the historical details that Thomas Häusler introduces in this volume. For example, he mentions reports published in the journal Der Deutsche Militärarzt during the Second World War on a phage preparation known as 'polyfagin', which was produced by the German pharmaceutical company Behringwerke as a treatment for dysentery. And he reveals that the research of René Dubos on phage therapy in 1942 was supported by a committee of the US National Research Council that was " assigned the task of keeping the country prepared for war". $\mathrm{He}$ also interviewed many of the researchers and business entrepreneurs who have been

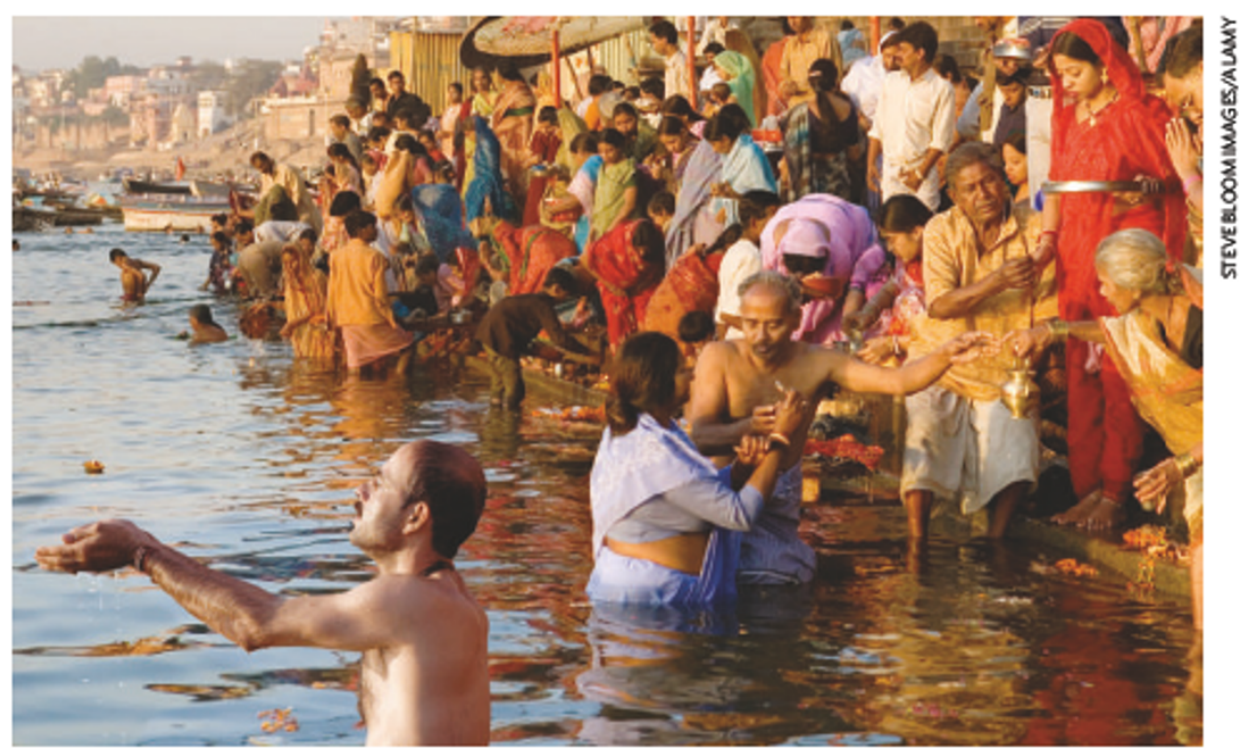

Troubled waters? Bathers in the Ganges were thought to be protected from cholera by phage. interested in developing phage therapy.

Much of this information will be useful for professionals as well as the general public. For example, I was interested to read of the progress made by Omnilytics (a company based in Salt Lake City) in the use and commercialization of phage for the treatment of bacterial spot disease in tomatoes.

However, like many 'popular' science books, the book often lacks a critical analysis of the information presented. For example, Häusler suggests that the spleen filters most phage from the circulatory system, whereas this task is largely done by the liver. He underplays the role of phage in causing human disease. $\mathrm{He}$ notes: ${ }^{\alpha}$ Prior to 1900 , diphtheria was the most frequent cause of death for German children." Two pages later he states that "phages are viruses that only attack bacteria ${ }^{p}$. He doesn't mention in this context that diphtheria toxin is encoded in a phage genome, so diphtheria is primarily a phage-associated disease. $\mathrm{He}$ also implies that the use of lysozymes to kill bacteria is new, but they have actually been used as food preservatives for decades. And there is no merit to his claim that lysin treatment, unlike antibiotic treatments, does not generate resistant mutants. Under laboratory conditions it might be hard to obtain the mutations needed to confer lysin-resistant phenotypes. But as most resistance comes from acquiring new DNA elements from nature, it is easy to see how the overuse of any lysin or antibacterial agent will select for those resistant elements that exist in nature, as has repeatedly happened before.

A more worrying aspect is Häusler's overuse of anecdotal cases. Although he states in the book's preface that the book ${ }^{\alpha}$ is not a health manual whose purpose is to testify to the efficacy of phages ${ }^{x}$, he refers to specific anecdotal cases in a way that suggests that phage therapy was indeed responsible for the reported clinical improvement. These treatments were often carried out in clinical settings that do not meet 
the current standards required for the certification of marketed pharmaceuticals. One of the cases, which is referred to numerous times throughout the book, involves an individual with a chronic bone infection who was treated by irrigation with solutions containing phage and by having phage-impregnated material placed in the open wounds. It would be interesting to compare such 'phage therapy' with the use of saline irrigations and sterile drains. Although Häusler acknowledges the need for the careful development of therapeutic agents, along with the need for adequate control experiments, there is a danger that this book might encourage some individuals with infectious diseases to use phage in such a way.

The development of therapeutic phage will need a commitment to meet all the scientific requirements for current pharmaceutical agents. An anecdotal approach, adopted by some of the investigators described in the book and widely used in clinical medicine in the early twentieth century, may retard rather then stimulate the acceptance of therapeutic applications. The encouraging results of animal experiments have demonstrated phage's capacity to rescue animals with life-threatening infections. Perhaps phage therapy, if carefully developed, could provide some much-needed antibacterial agents.

Sankar Adhya is at the Laboratory of Molecular Biology, National Cancer Institute, Bethesda, Maryland 20892, USA. Carl Merril is emeritus at the Laboratory of Biochemical Genetics, National Institute of Mental Health, Bethesda, Maryland 20892, USA.

\section{Eeyore goes to Washington}

\author{
The Beginner's Guide to Winning the \\ Nobel Prize: A Life in Science \\ by Peter Doherty \\ Columbia University Press: 2006.320 pp. \\ $\$ 24.95$
}

\section{Peter Parham}

Soon after my appointment as an assistant professor, I was interviewed in Palm Springs for a beginner's grant given by a popular American charity. The interviewer, a bejewelled and scarily tanned doctor, looked me straight in the eyes and barked, "So, for what will you win the Nobel prize?" On hesitating to answer, my interview was doomed. I shortly crawled away, to hear nothing more of the matter. Back then, what I could have used was The Beginner's Guide to Winning the Nobel Prize. The book's author, Peter Doherty, knows about these things, because in 1996 he and Rolf Zinkernagel were awarded the Nobel Prize in Physiology or Medicine for their joint work on the recognition of virus-infected tissue by $T$ lymphocytes of the immune system.

For the aspiring young scientist, or a student considering a scientific career, Doherty opens the vault to the world of science, explaining how it works and how to get on. His title is only lightly in jest, for the last chapter gives a common-sense set of 18 guiding principles to scientific success that almost any old hand would agree with. As well as continuing
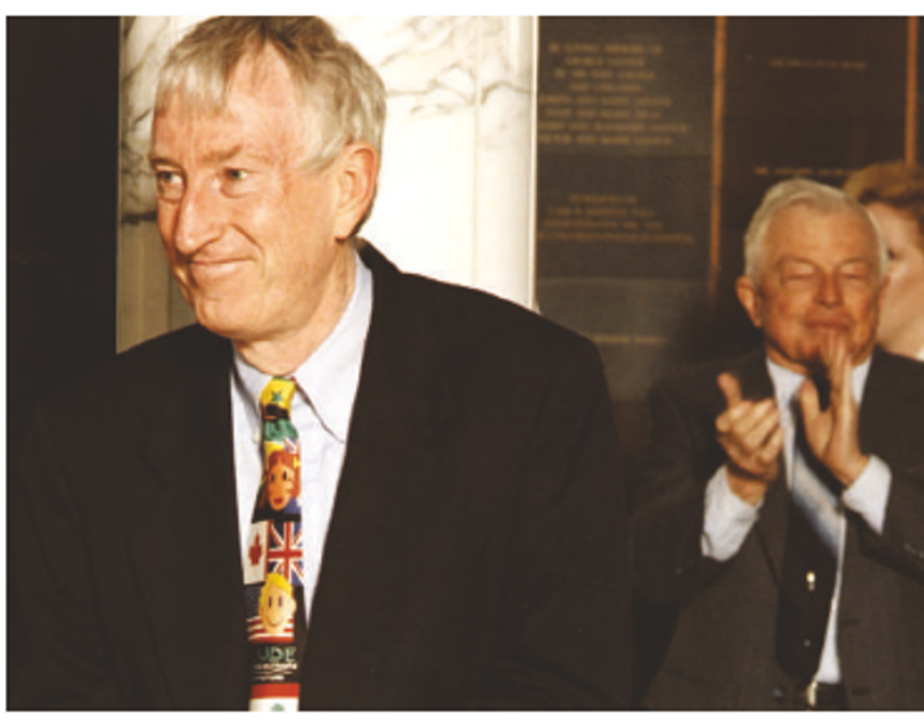

Winning a Nobel prize has given Peter Doherty a platform to air his views on climate change and the environment.

his kind, however, Doherty aims to reach a broader readership: those who learn from the movies that "scientists are always mad, bad or quaint nerds who rattle on about controlling the world".

$\mathrm{He}$ is not motivated by simple enthusiasm alone, however: like others in the know, Doherty has become deeply concerned with the way governments manipulate science to suit their political goals, and with the way publics at large, paradoxically, combine a pervasive suspicion of science with an equally pervasive confidence that technology - the application of science - can alone solve all the world's problems.

Doherty is an Australian, a veterinary surgeon and a faculty member at both St Jude Children's Research Hospital in Memphis, Tennessee, and the University of Melbourne. Once described by the eminent immunologist Philippa Marrack in The New York Times as "a bit Eeyore-like" (Eeyore being the indomitable, iflugubrious, donkey from A. A. Milne's The House at Pooh Corner), Doherty says that

\section{NEW IN PAPERBACK}

Nature: An Economic History

by Geerat J. Vermeij (Princeton

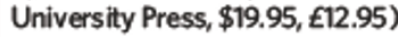

\section{On the Origin of Phyla}

by James W. Valentine

(University of Chicago Press,

$£ 22.50, \$ 35)$

"A magnificent book [about] ane of the most significant revolutions in the history of life, the Cambrian explosion." Stefan Bengtson,

Nature 430, 506 (2004).
Our Inner Ape: The Best and Worst of Human Nature

by Frans de Waal (Granta E9.99)

"In this excellent book for the public, Frans de Waal tackles some exasperating misconceptions about the evolution of the social behaviour of apes, particularly humans." Robert Sapolsky, Nature 437, 33-34(2005).
The Tree: A Natural History of What Trees Are, How They Live, and Why They Matter by Colin Tudge (Crown Publishers, \$27.95)

Pandora's Baby: How the First Test Tube Babies Sparked the Reproductive Revolution by Robin Marantz Henig (Cold Spring Harbor Laboratory Press, \$15.95)
The Equation That Couldn't Be Solved: How Mathematical Genius Discovered the Language of Symmetry by Mario Livio (Simon \& Schuster, \$15)

"Mario Livio follows [Galois'] brief existence like a sleuth... and gives a panoramic view of the direct, as well as quite remote, applications of group theory." István Hargittai, Nature 437, 34 (2005). 